\title{
FRANCESC EIXIMENIS Y LA POLÍTICA ESCOLAR DE LA CIUDAD DE VALENCIA (1389-1412)
}

\author{
José $\mathrm{M}^{\mathrm{a}}$ Cruselles Gómez ${ }^{1}$ \\ (Universitat de València)
}

\section{RESUMEN}

En el año 1399 el consejo municipal de la ciudad de Valencia encargó al teólogo Francesc Eiximenis la redacción de un reglamento para las escuelas de la ciudad. Se trataba de un proyecto polémico, ya que la política educativa causaba enfrentamientos entre el Consell y la catedral, pero también dentro del mismo gobierno municipal. La opinión de la oligarquía se encontraba dividida entre los partidarios del intervencionismo y los que defendían la completa libertad de enseñanza recogida en los Fueros del reino desde los tiempos del rey Jaime I. La obra de Eiximenis no hizo un tratamiento profundo ni decidido del problema. El franciscano asumía en un lugar los decretos conciliares que habían inspirado la normativa legal valenciana, para animar en otros la intervención de los poderes laicos. Su opinión (o su falta de opinión) refleja bien el comportamiento errático de la política escolar en el periodo 1389-1412, uno de los más convulsos de la historia medieval valenciana.

Palabras clave: Política escolar. Ideología educativa. Francesc Eiximenis. Escuelas. Enseñanza. Cultura.

\section{ABSTRACT}

In the year 1399 the municipal council of Valencia ordered the writing of the standing orders for the schools of the town to the theologist Francesc

1 Doctor en Historia. Profesor titular. Departamento de Historia Medieval. Facultad de Geografía e Historia. Universidad de Valencia. Av. Blasco Ibáñez, 28 46010 .València. C.e.: jose.m.cruselles@uv.es 
Eiximenis. It was a polemical project. The education policy caused confrontations between the Consell and the cathedral, but it also caused them inside the very municipal government The oligarchy opinion was divided among the supporters of interventionism and the ones who defended a complete freedom in teaching, which had been collected in the Fueros of the kingdom, when Jaime I was the king. The work by Eximenis did not do a very deep or decided treatment of the problem. Sometimes the Franciscan religious assumed the council decrees which had inspired the rules of the laws of Valencia, and sometimes he encouraged secular powers to take part. His opinion (or his lack of opinion) reflects very lively the erratic behaviour of the education policy in the period 1389-1412 one of the most convulsed of the medieval history of Valencia.

Keywords: School Policy. Educational Ideology. Francesc Eximenis. Schools. Teaching. Culture.

El día 27 de septiembre de 1399, el maestro Francesc Eiximenis, miembro de la orden franciscana, compareció ante el Consell de la ciudad de Valencia en compañía de tres hombres de leyes: los abogados Pere Catalá y Francesc Tallat, licenciados respectivamente en derecho canónico y civil, y el notario Pere Ferrando. En un momento anterior que en el acta de la reunión no se indica, el consejo les había encomendado verbalmente la delicada tarea de confeccionar un reglamento para las escuelas de la ciudad, que a decir de los munícipes, padecían desorden y abandono:

(...) que metessen en ordenació e en regla lo regiment e la lectura que, segons lur discreció, fer e tenir-se deguessen en les escoles de les arts de la present ciutat, les quals per negligència e colpa de passats paria ésser desordenades, e d'allò fessen relació en Consell. ${ }^{2}$

Ahora, una vez terminados sus trabajos, la comisión comparecía para dar cuenta de los resultados, expuestos en un escrito capitulado (reduit en escrits a manera de capitols) que, a instancias del Consell, Pere Catalá pasó a leer públicamente. Luego, y aunque los consejeros en su conjunto se mostraron favorables (e aquells lets, parech al dit Consell, segons dix e raonà, que estiguessen bé), unánimemente decidieron remitir el proyecto a los jurados, abogados de la ciudad y otros expertos, a fin de que comprobaran que nada de lo allí

2 Los fragmentos literales de las actas municipales de 1399 y 1400 corresponden a SANCHIS SIVERA, J., "La enseñanza en Valencia en la época foral", en Boletín de la Academia de la Historia, CVIII, 1936, pp. 147-179 y 661-696; CIX, 1936, pp. 7-80; especialmente CIX, pp. 43-45. 
estipulado contradecía la legislación foral. Una vez superado este último trámite, el nuevo reglamento debería ser puesto en práctica, para beneficio de los estudiantes que concurrían a las escuelas y del gobierno municipal. ${ }^{3}$

Sin embargo, las cosas no resultaron tan sencillas. Para empezar, el escribano del Consell no llegó siquiera a copiar aquel reglamento en el libro de actas, lo cual resulta significativo. No cabe duda de que la revisión del texto por parte de los jurados y los abogados de la ciudad arrojó serias dudas sobre su legalidad, y apenas transcurrido un año, el asunto dio lugar a una enconada polémica que los munícipes, indecisos quizás, trasladaron a la misma sala del Consell. El día 31 de agosto de 1400, fue convocado un número indeterminado de docentes (diverses maestres d'arts e de gramàtica aquí presents en la sala de la ciutat) que, en presencia de los jurados, sostuvieron un animado debate (fos verbal disceptació) sobre si las escuelas de la ciudad debían ser reunidas en un centro único, o si por el contrario convenía que siguieran manteniendo su pluralidad. El escribano, sin separarse demasiado de la parquedad habitual con que se levantaban estas actas (lo importante, al fin y al cabo, eran las decisiones adoptadas finalmente por los gobernantes), creyó necesario, al menos, reflejar el argumento principal que aducía cada parte. Así, sabemos que algunos de los reunidos defendieron la unificación de las escuelas, on tots los escolans de la ciutat hoissen e aprenguessen, porque en tiempos anteriores (antigament) se había hecho un reglamento (capitols) en este sentido. La opinión contraria se sostenía en que la diversidad escolar era mucho más provechosa para los estudiantes, no tanto porque pudiera abaratar los costes o porque facilitara la posibilidad de elegir maestro, sino explícitamente porque evitaba los inconvenientes y disputas que provocaría la reunión de tantos escolares en un solo centro. ${ }^{4}$

Esta última consideración era bastante certera, dada la proverbial aversión que el gobierno municipal sentía por todo lo que tuviera resonancias tumultuosas. De hecho, no falta quien considera que el temor al carácter revoltoso de los estudiantes, en buena medida inherente a las formas de socialización juveniles, desanimó la fundación de universidades en muchas de las grandes ciudades europeas de la Edad Media. Como señala Jacques Le Goff, el "género de vida" de una parte importante de la población estudiantil euro-

3 (...) que.ls dits capitols per extés sien regoneguts per los jurats e per los advocats pensionats, e altres que ells apel.lar-hi volran, a fi que.s confirmen e no desvien en res de o ab furs e privilegis; e fet açò, que sien meses en deguda execució, a bon regiment de les dites coses e correcció e instrucció dels escolans e altres confluens a les dites escoles, e per consegüent a la cosa pública de la ciutat dessús dita.

4 (...) fora perclusa via a dispendis e bregues per confusió de tanta multitud d'escolans unida a una escola. 
pea distaba mucho de la moral social de los burgueses y del "orden pacífico cotidiano" que éstos intentaban promover. ${ }^{5}$ Pese a que Eiximenis lo omitió en su utopía pedagógica, no podía por menos que ser consciente de semejante hecho. Si, como afirma Albert Hauf, acudió a las escuelas franciscanas de Oxford tras ser ordenado sacerdote en 1452, y realizó luego una serie de viajes escolares por Francia, Alemania e Italia antes de regresar a la patria en $1457,{ }^{6}$ bien pudo ser testigo de la revuelta que puso en estado de guerra a su alma mater oxoniense en febrero de 1455, cuando varios centenares de estudiantes armados atacaron a las fuerzas del orden, ocuparon la ciudad y se dieron al incendio y el pillaje durante unos cuantos días. El conflicto, que tuvo su origen en el intento de la guardia urbana por impedir una de las habituales peleas de taberna, supuso destrucción de bienes y pérdida de vidas humanas; por fuerza, la actividad universitaria debió verse seriamente afectada y, como solía ocurrir en casos similares, un buen número de escolares foráneos pudo desviarse temporalmente hacia otros centros. ${ }^{\top}$ Quizás se encuentre aquí la causa inmediata de alguna de las peregrinaciones académicas de Eiximenis, y la razón de que finalmente volviera a casa sin haber obtenido el doctorado.

Sin embargo, aquel día de agosto en que los maestros discutieron en la sala del Consell acerca del futuro de la enseñanza escolar, los jurados de Valencia no se mostraron muy conmovidos por la tesis de la turbulencia estudiantil. Lo que verdaderamente les preocupaba era, precisamente, el reglamento escolar redactado un año antes por Eiximenis y sus compañeros, y el hecho de que en él se estableciera, como alguno de los presentes se apresuró en señalar, la unificación de las escuelas. Al cabo, los munícipes tomaron una decisión fundamentada en cuatro considerandos. El primero, que entre los expertos convocados como consejeros para la ocasión, no había acuerdo respecto a la forma de proceder; el segundo, que el reglamento en cuestión excedía la legislación foral, y en concreto una norma que databa de los tiempos de Jaime I, en la que se permitía a cualquier persona abrir escuela en la ciudad sin pagar impuesto alguno; el tercero, que dicho reglamento nunca había llegado a entrar en vigor, justamente porque contradecía los fueros del reino; y el cuarto, que alguien (indeterminado) había abusado de un reglamento sin validar.

5 LE GOFF, J., "Las universidades y los poderes públicos en la Edad Media y en el Renacimiento", en Tiempo, trabajo y cultura en el Occidente medieval, Taurus, Madrid 1983, pp. 189-210.

6 HAUF, A., "Francesc Eiximenis", en EIXIMENIS, F., Lo Crestià (selecció), ed. de A. Hauf, Edicions 62, Barcelona 1983, pp. 6-7.

7 SALTER, H.E. (ed.), Munimenta civitatis Oxonie, G. Simpson, Devizes 1920, pp. 126128. 
Cabe preguntarse, respecto al primer argumento, si los jurados no convocaron aquella reunión de maestros con plena conciencia de cuál iba a ser el resultado, precisamente para que la constatación del disenso reforzara el segundo y más importante considerando, el del contrafuero. Por otra parte, las dos últimas premisas permiten intuir qué había ocurrido en el año transcurrido desde que la comisión de Eiximenis había presentado el reglamento escolar ante el Consell. Ambas premisas eran, en la argumentación de los jurados, subsidiarias del considerando principal, el segundo, pues venían a justificar la perentoria necesidad de restablecer el orden foral: los jurados debían impedir que se siguiera haciendo un mal uso de una normativa ilegal y nunca aprobada oficialmente.

¿Alguien había recurrido al reglamento en cuestión para intentar cerrar alguna escuela? Probablemente algún maestro, porque en el corolario añadido a la decisión final de los jurados, se indicaba expresamente que ningún maestro podría oponerse a que cualquiera de sus colegas abriera escuela propia. También es posible que la juraduría anterior, la que un año antes había impulsado la redacción del reglamento escolar, hubiera intentado aplicarlo de facto antes de su aprobación definitiva. En cualquier caso, los estatutos redactados por la comisión de Eiximenis fueron declarados nulos y sin efecto, sots qualsevol concepció de paraules sien concebuts, lo que no significa que el episodio en cuestión no tuviera trascendencia alguna. ${ }^{8}$ Volveremos sobre ello. Ahora importa que extraigamos dos conclusiones que tienen, a su vez, carácter instrumental en nuestra exposición. La primera es que lo que estaba en el centro de la discusión era el control de la oferta en el sector educativo, lo que implicaba la regulación de la competencia entre los maestros y también el papel que en dicha regulación debían jugar los dos poderes jurisdiccionales que se repartían el espacio urbano: el municipio y la iglesia. La segunda, que la política escolar del municipio tenía muy dividida la opinión de sus gobernantes, y si unos se mostraban partidarios de una intervención decidida en el sector, otros estaban igualmente dispuestos a impedirla. El resultado fue una política errática que, favorecida por la alternancia anual en la composición de la juraduría y el consejo, resultó particularmente incierta durante el periodo 1389-1412, por otro lado uno de los más convulsos en la historia del municipio medieval valenciano. ${ }^{9}$

8 La decisión tomada por los jurados tras asistir al debate entre los maestros, fue ratificada solemnemente en la reunión del Consell celebrada el 15 de septiembre de 1400 (SANCHIS SIVERA, "La enseñanza en Valencia", CIX, pp. 44-45).

9 Periodo enmarcado entre dos momentos críticos de particular trascendencia: el asalto de la Judería en 1391 y el interregno en 1410-1412 (NARBONA VIZCAÍNO, R., "El trienio negro: Valencia, 1389-1391. Turbulencias coetáneas al asalto de la judería", En la España Medieval, 35, 2012, pp. 177-210). 
Pongámonos en antecedentes. Hasta bien entrada la segunda mitad del siglo XIV, la enseñanza escolar estuvo bajo el control indiscutido del obispo. Por supuesto, el fuero del rey Jaime protegía el concurso de todos los maestros, laicos y clérigos, y les eximía de pagar tributos por enseñar (como se eximía a los ciudadanos del pago de otros impuestos), pero no pretendía discutir la primacía ideológica y organizativa del obispo, como hubiera ocurrido en caso de reclamar para la administración regia la concesión de la licencia docendi, es decir, la capacidad de juzgar las aptitudes técnicas y morales de los maestros. ${ }^{10}$ Por otra parte, los edictos conciliares y otros documentos pontificios muestran que la erradicación de la simonía escolástica constituía un pilar importante de la ideología educativa de la Iglesia: siendo necesario que cualquier docente obtuviera del obispo o de sus representantes la licencia para enseñar, era doctrinalmente inadmisible que ésta se vendiera. El fuero valenciano participa de la esencia de las admoniciones papales de la época, e incluso muestra coincidencias casi literales con el tenor de alguna de ellas. Así, en una carta remitida en 1171 a los obispos de Francia, el pontífice Alejandro III intentaba impedir que se siguiera vendiendo la licencia docendi, y recordaba a los prelados que debían asegurarse de que cualesquiera personas capacitadas para ello, pudieran abrir escuelas de letras sin sufrir impedimento ni exacción alguna. ${ }^{11}$ En Valencia, y según afirma Sanchis Sivera, la escuela sufragada por el obispo y el cabildo catedralicio se creó en 1259, aunque desde 1240 existía un praesentor o chantre a quien se había encomendado la supervisión de las escuelas que pudieran abrirse en la ciudad, lo que incluiría la concesión de la licencia docendi a los maestros. Sin embargo, un estatuto dictado por el arzobispo de Tarragona en 1242, luego confirmado por el papa Inocencio III, anuló la necesidad de contar con el permiso del praesentor para abrir escuelas de salmos, canto y gramática, y recordaba que el derecho de examinar a los maestros correspondía sólo al obispo. ${ }^{12}$

10 Atorgam que tot clergue o altre hom pusque franchament e sens tot servii e tribut tener estudi de gramática e de totes altres arts e de fisica e de dret civil e canònich, en tot loch per tota la ciutat (Furs de València, ed. crítica de G. Colón i A. Garcia, vol. VIII, Barcino, Barcelona 1999, p. 140).

11 (...) ut quicumque viri idonei et litterati voluerint studia regere litterarum, eos, sine molestia et exactione qualibet, scholas regere patiantur (MANACORDA, G., Storia della scuola in Italia, vol. I: Il Medio Evo, parte I: Storia del diritto scolastico, Remo Sandron, Palermo 1914, pp. 80-81).

12 (...) quod quicumque docere voluerit pueros in psalmis et cantu et gramatica possit hoc facere sine licencia precentoris; sed examinatio magistrorum pertineat ad episcopum sicut in quibusdam ecclesiis de consuetudine est obtentum (SANCHIS SIVERA, "La enseñanza en Valencia", CVIII, pp. 153-156, y especialmente 155n). 
Todas estas medidas estaban en consonancia con los preceptos enunciados en los Concilios de Letrán de 1179 y 1215, en los que la Iglesia había afirmado su vocación educadora de la sociedad cristiana, abriendo a los laicos las escuelas en las que se formaban los clérigos, y estableciendo el carácter gratuito de la enseñanza que se impartía en ellas. Las escuelas catedralicias, que los obispos tenían la obligación de mantener asignando a los docentes las rentas eclesiásticas correspondientes, constituían el eje principal de un sistema educativo que se miraba en los principios de la Reforma Gregoriana, y que tenía, como la propia iglesia del siglo XIII, una evidente vocación urbana. El franciscano Eiximenis participaba de esa misma vocación y era buen conocedor de una normativa a la que no dudó en atribuir un lugar destacado dentro de su concepción teológico-histórica del valor del conocimiento, según la expresaba en los primeros capítulos del Dotzè del Crestià. Si el hombre necesitaba huir de la ignorancia para conocer a Dios y ganar la salvación, y si la ciudad constituía el mejor lugar del mundo para aprender, la Iglesia había puesto en la ciudad los medios precisos, es decir, maestros y escuelas gratuitas:

Per rahó, donchs, que en les ciutats cascú haja manera de informar si mateix, ha hordonat la santa mare Esgleya, segons que appar in quinto Decretalium, titulo De magistris, que cascuna esgleya catradal haja mahestres qui ensenyen a.quells qui volran apendre gramàtiqua o altra facultat que lesquen, e en les seus metropolitanes hagen un theòlech qui liga teologia. E tots aquests dits ligents lesquen francament ne.n demanen res, especialment als pobres. E manà aquí lo papa que les dites esgleyes sien tengudes de assignar provisió als dits legents per tal que no.ls calla res reebre dels pobres escolans a qui ensenyen. E manà aquí lo papa Alexandri, sots gran pena, que nagú no gos empatxar aquell qui volrà legir dret, o altra leguda sciència e bona, si emperò serà lo legidor aquell apte per legir. ${ }^{13}$

Aquí está, al final del párrafo, la libertad eclesiástica de enseñanza, una ortodoxia con la que comulgaba nuestro franciscano, pero que transferida a la legislación foral valenciana propició el fracaso del proyecto reglamentista de 1399, en cuya redacción había tomado parte de manera, como vemos, poco acorde con sus propias ideas. En realidad, cabe decir que Eiximenis, y al contrario de lo que ocurría con otros muchos asuntos relacionados con la enseñanza (sobre todo en sus aspectos más privados), no tenía criterios firmes en lo tocante a la política educativa, debido probablemente a que su concepción escolástica del saber se encontraba, en este punto, huérfana de referentes autorizados. ¿Dónde estaban, cuando más necesarios eran, los Aristóteles, Juan de Gales o Maestros de Sentencias que pudieran iluminarle en un asunto tan espinoso? Para establecer el papel que tocaba cumplir a

13 EIXIMENIS, F, Dotzè llibre del Crestià, parte I, vol. 1, edición de Xavier Renedo et al., Universitat de Girona-Diputació de Girona, Girona 2005, p. 27. 
los poderes laicos en la necesaria escolarización de la sociedad urbana, no encontró otro recurso de autoridad que un oscuro historiador de la época de Augusto, llamado Pompeyo Trogo:

Per tal deya Trogus Pompeius que los nobles prínceps e naturals senyors en special deuen attendre, per tal que tota lur senyoria sia il.luminada e plena de lum de veritat, que facen per les ciutats lurs fer estudis especials de diverses sciències, specialment de gramàtica, lògica, philosophia e poecia. E en qualque ciutat apte de llur senyoria o ciutats facen fer studis generals on sos vassalls trameten lurs infants per apendre allò mateix, o dret civil, o canònich, o theologia, o medecina, o so qui.ls sia pus profitós. E ells, per favorejar la sciència, de llurs pròpies rendes o regalies deuen aquí los ligents provehir copiosament e vedar-los que de nagú res no gesen pendre, per tal que per fretura negú no s'haja estar de apendre. ${ }^{14}$

Eso es todo. Los príncipes y señores debían procurar que sus ciudades estuvieran provistas de estudios "especiales" o "particulares" donde se enseñaran las artes liberales, y promover en alguna de dichas ciudades la creación de un estudio "general" donde, además de aquellas, pudiera aprenderse derecho civil y canónico, medicina y teología. Prescindiendo de una larga tradición del pensamiento jurídico que vinculaba el estudio general a la acción creadora de las monarquías universales, Papado e Imperio; e ignorando la opinión algo más reduccionista de su admirado Tomás de Aquino, que reservaba en exclusiva dicha creación al papa, Eiximenis parece abrazar una doctrina en auge, que había tenido en las Siete Partidas una de sus primeras manifestaciones, y que estaría plenamente madura en los últimos años del siglo XV, la de "regionalizar" el concepto de estudio general, al que se había encomendado originalmente "el cuidado de los intereses científicos de la comunidad imperial cristiana", para adaptarlo a una realidad territorial y jurídica limitada, la de los nuevos estados principescos. ${ }^{15}$ Podemos pensar que el franciscano se sentía movido a ello por su condición de consejero y protegido de los reyes de Aragón, pero el tratamiento que hace del problema es tan conciso y superficial que difícilmente podemos asegurarlo. En ningún caso especifica si, en materia escolar, el gobierno ciudadano compartía las funciones del príncipe. Reitera ad nauseam la bondad educativa del medio urbano, el deber pedagógico de los padres con los hijos, la gran recompensa que el esfuerzo didáctico prometía al individuo mismo, pero ni una palabra respecto a las obligaciones del municipio en un asunto que, resultando de importancia capital para los ciudadanos, por fuerza debía serlo también para la cosa pública. Ninguna prescripción, ningún consejo...

14 Ibídem.

15 ERMINI, G., "Concetto di Studium Generale", en Archivio Giuridico, 127, 1942, fasc. 1 , pp. 3-24. 
Otro problema: el dinero. Si en su lacónica concepción de la política educativa de los poderes laicos correspondía al príncipe abrir escuelas, y añadiendo nosotros la suposición de que semejante encargo se hiciera extensible implícitamente a municipios como Valencia -puesto que su ámbito de poder formaba parte de la jurisdicción del príncipe-, ipodemos pensar que las escuelas que fundaran estos últimos debían ser también gratuitas, como las del príncipe o las de la Iglesia? Porque si el príncipe estaba obligado a pagar de su bolsillo a los maestros, y además hacerlo copiosament, no quedaría más remedio que rascar las arcas municipales, y esto no dejaba de ser un problema. Aunque no conocemos el texto de las ordenanzas escolares de 1399, dudo seriamente que recogieran semejante propuesta. El Consell de Valencia, con los jurados la cabeza, podía estar dispuesto a distraer algunos fondos en la empresa, pero no a instituir la educación universal y gratuita, ni mucho menos. De manera encomiable, pero harto banal, nuestro bienintencionado franciscano hacía extensible a las escuelas laicas el principio gregoriano de la gratuidad del conocimiento, don divino cuyo mercadeo constituía pecado de simonía, y ello sin pararse a considerar que, en la cruda realidad de los hechos, las escuelas eclesiásticas hacía mucho tiempo que habían dejado de ser gratuitas, si es que lo habían sido en algún momento.

En la Europa de finales del siglo XII, y con muy contadas excepciones, sólo la Iglesia tenía los medios necesarios para asumir la tarea de enseñar, es decir, hombres versados en letras y una red capilar de parroquias que servía como marco de encuadramiento religioso, político y educativo de la población. El carácter eclesiástico del magisterio, el monopolio episcopal de la instrucción literaria, se había alimentado del desinterés y la incapacidad de los poderes feudales laicos desde los tiempos de la descomposición carolingia; y el desarrollo del derecho canónico, que dio carácter normativo a lo que sólo era fruto de una práctica consuetudinaria, acabó de fortalecerlo. ${ }^{16}$ Cuando comenzó la época de las ciudades y surgieron nuevos grupos para los que el aprendizaje de las letras constituía una parte importante de sus estrategias de reproducción social, sólo la Iglesia era capaz de satisfacer tal demanda. La decisión de abrir las escuelas a los laicos ampliaba las oportunidades de extender la ideología clerical al conjunto de la sociedad urbana, pero también sometía las instituciones educativas eclesiásticas a poderosos

16 Los decretos conciliares no obligaban a conferir a un clérigo la dignidad de magiscola, cargo responsable de las escuelas catedralicias y en general del control de los docentes; sin embargo, el papa Alejandro III reclamaba que, en caso de que se produjera semejante situación, el laico electo para el cargo fuera inmediatamente tonsurado y ordenado (MANACORDA, Storia della scuola in Italia, pp. 89-94). 
estímulos transformadores cuyo dinamismo rebasó pronto las defensas que la reforma gregoriana oponía al avance de los valores seculares. El dinero. En una sociedad donde la división del trabajo y la compraventa de bienes y servicios progresaban rápidamente, la instrucción literaria se convirtió en un producto de intercambio más, y los maestros eclesiásticos quedaron colocados al borde de la simonía.

En cumplimiento de los preceptos lateranenses, y al menos desde 1259, la catedral de Valencia contaba con una escuela de gramática cuyos docentes eran clérigos que se mantenían con sus correspondientes beneficios. En algún momento entre finales del siglo XIII y principios del XIV, el obispo estableció además una subvención directa que, cumpliendo las instrucciones de la sede pontifica, pretendía atender las necesidades materiales de aquellos maestros que no disponían de las rentas eclesiásticas suficientes para mantener sus vidas con dignidad. En 1317 dicha subvención era de 12 dineros al día, y se entregaba a cambio de la obligación explícita de enseñar a los escolares pauperes. No sabemos si en este momento se diferenciaba ya entre los estudiantes pobres que aprendían gratuitamente merced a la subvención episcopal, y los que no lo eran y pagaban al maestro el salario correspondiente, pero en 1351 la distinción estaba plenamente establecida; para entonces, los maestros que regían la escuela capitular de gramática obtenían sus ingresos de tres fuentes complementarias: sus propios beneficios eclesiásticos, los subsidios asignados por el obispo y el cabildo, y los pagos exigidos a los escolares. Sólo los pobres podían aprender gratis, y ya se ocuparon los docentes de aumentar la presión sobre ellos en los tiempos siguientes. En 1368, el maestro capitular Guillem Crexell, presbítero y bachiller en artes, procedió a confiscar los libros y otras propiedades de los alumnos que no le pagaban, de manera que el obispo se vio obligado a intervenir para evitar el escándalo, y le conminó a devolver todos aquellos bienes, recordándole que tenía la obligación de enseñar gratuitamente a los escolares becados por el cabildo catedral y a otros estudiantes pobres, definiendo como tales a aquellos que no contaban con medios propios de subsistencia. ${ }^{17}$

Extinto el principio de gratuidad de la enseñanza, y no existiendo interdicción canónica al respecto, la escuela capitular se abrió también a los maestros laicos. El primero que encontramos al frente de dicho centro es el

17 El maestro debía atender gratuitamente a los scolares dotabiles de Capitulo supradicto et alios pauperes taliter quod non habeant unde vivant (SANCHIS SIVERA, "La enseñanza en Valencia", CIX, pp. 29-30). Esta y otras cuestiones relativas a la evolución del mundo escolar valenciano de los siglos XIII-XV, pueden seguirse en CRUSELLES GÓMEZ, J. M., Escuela y sociedad en la Valencia bajomedieval, Diputación de Valencia, Valencia 1997. 
bachiller Pere Figuerola, que permaneció en el cargo, al menos, entre 1359 y 1364; y en 1373, cuando tuvo lugar el conflicto con el municipio, el regente era otro laico, el maestro Gil Remírez. Sanchis Sivera sugería la existencia, desde el momento mismo de la conquista, de una organización escolar descentralizada, donde la escuela capitular ocupaba un lugar relevante, pero que contaba también con escuelas parroquiales y otras en manos de maestros privados o "libres", entre los que se contaban tanto clérigos como laicos. Los fueros del reino protegían la libertad de enseñanza, al igual que hacía la legislación eclesiástica, que encomendaba al obispo el control de los docentes a través del pertinente examen de sus capacidades, pero no le facultaba para imponer ningún tipo de monopolio. Los problemas vinieron cuando la autoridad eclesiástica intervino en los conflictos desatados entre los diferentes maestros, clérigos la mayor parte de ellos, por cuestiones de competencia profesional que sólo se explican por el incumplimiento generalizado del precepto de gratuidad. La concurrencia de escuelas vecinas erosionaba los salarios de los maestros, y éstos reaccionaban intentando obtener del obispo las licencias monopolísticas que les permitieran desembarazarse de los competidores; ${ }^{18} \mathrm{y}$ al entrar en ese confuso juego, la autoridad eclesiástica terminó favoreciendo la aparición de un nuevo fenómeno: la intervención municipal. Con todo, las relaciones entre iglesia y municipio en torno a la cuestión de la enseñanza no fueron necesariamente conflictivas, y existen muestras de colaboración más o menos decidida tanto en Valencia como en otros lugares del entorno peninsular. También se dieron casos en los que uno de dichos poderes tomó la iniciativa, y la aquiescencia o el desinterés del otro evitó desavenencias. Allí donde los municipios no tenían medios para intervenir, el obispo hacía y deshacía sin otra oposición que la de los maestros libres; en otros lugares la autoridad laica fue más decidida, y si en un principio se hizo eco de las necesidades educativas de la población para trasladarlas al obispo, al cabo decidió desmarcarse de su tutela e intervenir por sí misma en el sector.

El conflicto que tuvo lugar en 1374 entre el obispo y los jurados de Valencia, apoyados respectivamente por el Cabildo catedral y el Consell de la ciudad, supuso una alteración severa de los marcos institucionales que hasta entonces habían regulado el concurso de la oferta educativa, y marcó de forma decisiva el periodo siguiente, que podemos extender hasta

18 Sanchis Sivera reunió un puñado de documentos muy expresivos al respecto, que ilustran la intervención del obispo en las escuelas de Valencia, Sagunto, Jérica, Sueca, Albaida o Gandía (SANCHIS SIVERA, "La enseñanza en Valencia", CVIII, pp. 162165). 
la fundación y posterior fracaso de la Escuela Mayor de 1412. El origen del problema estuvo, precisamente, en un intento de colaboración entre ambos poderes. El 4 de marzo de 1373, el consejo aprobó la adquisición de un inmueble donde pudieran instalarse los maestros de la ciudad, y especialmente el de la escuela capitular (aquell qui és apel-lat de Capitol), aduciendo que no contaban con un lugar estable y apropiado, y que esto redundaba en perjuicio de los escolares. ${ }^{19}$ La decisión se justificaba de manera implícita en la negligencia con que la iglesia gestionaba su escuela, pero el objetivo no era crear una escuela municipal que compitiera con aquella, o por lo menos no parece haberlo sido en un primer momento. El Consell se conformaba con adoptar un papel subalterno, y corría con los gastos de instalación de una escuela cuya gestión y control ideológico seguiría correspondiendo, como era costumbre, al obispo y el Cabildo. El 23 de septiembre de ese mismo año se formalizó la compra de unos amplios locales ubicados en la parroquia de Sant Bartomeu, que en adelante serían conocidos como escoles de Valldigna por su cercanía a la casa que el monasterio mantenía en la ciudad, y en los que el municipio instaló al maestro capitular, Gil Remírez, en régimen de alquiler a precio reducido. Para entonces, sin embargo, había sido elegidos unos nuevos jurados que estaban decididos a crear su propia escuela, y el 26 de septiembre remitieron una carta a Guillem Querol, un maestro en artes de origen valenciano que residía en Barcelona, ofreciéndole dirigir la que ya sin tapujos llamaban escola major. La justificación que hacían entonces del intervencionismo municipal encontraba fundamento en el mismo estado de cosas que había conducido a la compra de las casas (d'alcun temps a ençà les escoles en arts d'aquesta ciutat no han aquell bon recapte que.s mereixeria), pero si antes ocurría que los maestros de la ciudad no encontraban los locales adecuados, ahora la situación se había complicado por las disputas entre dichos maestros, cada uno de los cuales pretendía hacerse cargo de la nueva escuela en perjuicio de los intereses de sus colegas. Y había sido el médico Pere Figuerola, antiguo regente de la escuela capitular reconvertido en asesor municipal, quien había identificado el origen del problema: ninguno de los maestros tenía la capacidad y la titulación necesarias para destacar sobre los otros:

(...) entre.ls maestres que ací mostren non havia alcú bé endreçat e graduat, tal que.ls altres l'aguessen entre sí per major e per pus covinent a tenir la Major

19 (...) per aquesta rahó los escolans fills dels bons hòmens de la dita ciutat, e altres, perdien lur temps e avien altres dans a vegades (VIVES LIERN, V., Las casas de los estudios en Valencia. Informe acerca del sitio en que éstas se hallaban emplazadas, Ayuntamiento de Valencia, Valencia 1902, p. 16). 
Escola, ans cascú cuydava saber e valer, e per ço eren en divisió e enveja per aver cascú lo dit alberch e Escola Major. ${ }^{20}$

En consecuencia, los jurados habían decidido traer de fuera de la ciudad un solemne mestre y, a propuesta de Figuerola, ofrecían el cargo al mencionado Guillem Querol per vostra sufficiència de saber e de bones costums, y también porque siendo natural de Valencia, su nombramiento redundaría en honor de la ciudad y de sus gobernantes (ans encara per nostra honor e de la ciutat, en tant com vos e los vostres fos e sots naturals d'aquella). Le pedían, eso sí, que en caso de no aceptar la oferta lo notificara rápidamente, porque el curso escolar estaba a punto de comenzar (car poch temps havem tro al principi de l'estudi). El Consell no se había retractado de su decisión de instalar en las escuelas de Valldigna al maestro del Cabildo, pero pretendía utilizar parte del inmueble para crear una escuela nueva, subvencionada esta vez por la autoridad laica, que por su tamaño, prestigio y clientela pasara a convertirse en la escola major, es decir, en el paradigma de las restantes escuelas de la ciudad, incluida la del Cabildo, que se vería relegada a una posición secundaria. Los munícipes declaraban abiertamente su intención de sustituir la primacía episcopal en materia escolar por la suya propia, y contando ya con las instalaciones adecuadas, buscaban un maestro desvinculado del poder eclesiástico y de los intereses del grupo de docentes que ya ejercía en la ciudad.

Guillem Querol no vino finalmente a Valencia, pero los jurados siguieron adelante con sus planes: tan sólo necesitaban encontrar otro candidato. El conflicto con el obispo y el Cabildo estalló en el verano de 1374, a decir de los jurados, porque aquellos pretendían que no hubiera sino una escuela en la ciudad, y para conseguirlo fulminaban vetos y excomuniones sobre los restantes maestros:

(...) s'esforçaven que fos tenguda en la dita ciutat solament una escola e no pus, $e$ així que per vet o per excomunicació o per altres vies directes e indirectes, s'esforçaven vedar o contrastar alcuns volents tenir escola o escoles de les dites arts). ${ }^{21}$

Reunido el 14 de agosto de 1474, y ante tantas dificultades, el Consell decidió dar marcha atrás en su política intervencionista y vender la casa de las escuelas de Valldigna, encargando a los jurados que formaran una comisión para negociar con la iglesia el asunto de las escuelas. Un mes más tarde,

20 Los fragmentos de la carta enviada por los jurados a Guillem Querol corresponden a la edición de SANCHIS SIVERA, "La enseñanza en Valencia", CIX, pp. 40-41.

21 Este y otros fragmentos del acta de la reunión del Consell de Valencia celebrada el 17 de septiembre de 1474, y del pregón municipal del día siguiente, corresponden a TEIXIDOR, J., Estudios de Valencia (Historia de la Universidad hasta 1616), ed. de L. Robles, Universidad de Valencia, Valencia 1976, p. 99. 
en la reunión celebrada el 17 de septiembre, los jurados daban cuenta al Consell de sus gestiones, desgranando los detalles de un conflicto que había devenido en farsa.

Tras recibir el encargo negociador, y antes que nada, los jurados habían despachado consultas con algunos juristas y otros prohombres, concluyendo que la actitud del obispo dañaba aquellos fueros del reino que permitían a cualquier persona abrir escuela en la ciudad; también que, como demostraba la experiencia, no era provechoso para la cosa pública que en la ciudad hubiera una sola escuela. A continuación, poniendo en actos sus decisiones, habían instalado a un nuevo maestro, el bachiller en artes Pere Costa, en las escuelas de Valldigna, los locales municipales donde también enseñaba el maestro de la catedral, Gil Remírez, con quien entró en competencia inmediatamente. La reacción del obispo fue intempestiva: había llevado preso a Pere Costa y lo había encarcelado, y cuando los jurados fueron a pedirle explicaciones, les contestó que el maestro era tonsurado y que estaba bajo su jurisdicción, despachándolos con malos modos. ${ }^{22}$ Los jurados decían estar seguros de los motivos del prelado: tenía un trato con el maestro capitular, Gil Remírez, que le pagaba para espantarle la competencia:

(...) car lo dit senyor bisbe, per convinenza feta entre aquell, d'una part, e mestre Gil Remírez de la part altra, havia e prenia certa quantitat del dit mestre Gil per ço que.ll solament regís la dita escola, e fos una tan solament).

Era la gota que colmaba el vaso. Los bienintencionados jurados se las tenían, nada menos, que con un obispo simoníaco; y ante aquella cosa mala e reprovada, estaban justificadas las medidas más drásticas. El maestro Gil Remírez era inquilino del municipio en las escuelas de Valldigna, de manera que los munícipes echaron mano a la contabilidad y, como comprobaron que no estaba al día en el pago del alquiler, lo hicieron prender y encarcelar; luego se fueron al obispo y le propusieron un canje, a lo que el muy terco volvió a negarse. Y como ya no se les ocurría qué más hacer, volvían ahora para consultar al Consell. El correspondiente debate entre los consejeros fue largo y vehemente (fo molt rahonat e disputat), llegando a proponerse procedimientos expeditivos, aunque acordes, eso sí, con los fueros y privilegios (foren cercats, trovats e concordats alcuns remats e proceiments introduits e leguts per furs e privilegis); pero finalmente se impuso la sensatez y tomaron la decisión de no hacer nada irreparable antes de volver a hablar con el obispo. Así que una nueva comisión, encabezada por uno de los jurados, se encaminó otra vez hacia el palacio episcopal para participarle lo que el Consell

22 (...) que.l dit en Pere Costa era coronat e de son for, e que ell sabia per què.l tenia pres, que no.n haguessen cura los dits jurats. 
haría en caso de que no se aviniera a razones, cosa que le rogaban hiciera. Por fin, el obispo accedió a tan suplicantes amenazas y soltó a Pere Costa, que inmediatamente fue llevado por los miembros de la comisión hasta la sala donde seguía reunido el Consell, que en ese mismo momento dio orden de liberar a Gil Remírez.

En medio de tales despropósitos tocó a su fin el primer ensayo de la política educativa municipal. Al día siguiente, 18 de septiembre, los jurados hicieron publicar un pregón donde denunciaban las intenciones monopolísticas de "algunos", y declaraban solemnemente su adhesión al texto literal del antiguo fuero del rey don Jaime, así como su decisión de defenderlo contra todos aquellos que pretendieran conculcarlo. ${ }^{23}$ Las escuelas de Valldigna fueron divididas en dos partes y vendidas a los maestros que las ocupaban, Gil Remírez y Pere Costa, que una vez excarcelados siguieron ejerciendo la docencia en dicho inmueble hasta los primeros años del siglo XV. ${ }^{24} \mathrm{Al}$ final, los jurados y el Consell se habían salido con la suya, porque en 1374, y al contrario de lo que pensaba Sanchis Sivera, su pretensión no había sido unificar las escuelas de la ciudad (es decir, reunir a los maestros en un solo inmueble y prohibir que se ejerciera la docencia en otros lugares), sino abrir una escuela municipal que hiciera la competencia a la escuela capitular, y en definitiva quebrar las prácticas monopolistas del obispo (contrarias, no lo olvidemos, a los preceptos conciliares), poniendo en discusión el derecho de control de la enseñanza escolar que la autoridad eclesiástica había adquirido por vía consuetudinaria. Sin embargo, en su enfrentamiento contra las prerrogativas del clero, el municipio había invocado la libertad foral de enseñanza entendida de manera omnímoda, y no sólo como exención fiscal. Quizás esto era inevitable, porque en 1359 y en el contexto de un conflicto de competencias con el municipio de Sagunto, el propio obispo había recurrido ya al fuero en cuestión para sostener los derechos del maestro designado por él. ${ }^{25}$ A partir

23 (...) que com alcuns hajen intenció que escola o estudi de gramàticha o d'altres arts, en la dita ciutat no.s puxa ne.s deya tenir sinó en cert nombre o en certa manera, lo contrari de lo qual és ordenat expressament per fur (...) e entenen (els jurats) aquelles defendre e mantenir si per alcun o alcuns era assejat lo contrari.

24 Pere Costa volvió a ser encarcelado en 1396, esta vez a instancias del síndico municipal, porque adeudaba una parte del precio del inmueble (Archivo del Reino de Valencia, Justicia Civil, 2488 bis, fol. 23).

25 La interpretación que el prelado hizo entonces del fuero, se alejaba ligera pero significativamente del tenor original de aquel, puesto que añadía una condición de pericia que para nada estaba en el texto, sino que procedía de la tradición normativa eclesiástica: Cum de iure et secundum forum Valentie ac alias, licitum existat cuiumque experto et volenti docere scolares, docendi ... et tenendi ac regendi scolas publice in civitate et regno Valentie (SANCHIS SIVERA, "La enseñanza en Valencia", CIX, pp. 27-28). 
de aquí, y hasta los últimos años del siglo XV, el viejo fuero pesó como una losa sobre las intenciones ordenancistas del gobierno municipal en materia escolástica. Para poner fin al control eclesiástico del sector, el Consell había comprometido gravemente su propia capacidad de regularlo, propiciando dentro de su propio seno, y por tanto en el de la clase dirigente ciudadana, una discusión interminable entre los intervencionistas, firmes defensores de la reglamentación pública, y los foralistas, partidarios más bien de confinar la enseñanza al ámbito de los asuntos privados.

La intervención tenía a su más destacado activista en el maestro en artes y medicina Pere Figuerola, un lulista formado en la universidad de Montpellier, que fue examinador municipal de médicos, autor de diversos tratados sanitarios y consejero de los jurados durante el anterior conflicto escolar con el obispo. ${ }^{26}$ En la reunión del Consell celebrada el día 28 de septiembre de 1389, cuyo asunto principal era nombrar un nuevo mostassaf, Figuerola presentó un proyecto de reglamento escolar que él mismo había compuesto a ruegos de algunos ciudadanos influyentes, y que redundaban, por supuesto, en beneficio de los estudiantes y del gobierno municipal:

(...) fossen oferts al dit Consell e dits en substància uns capitols, los quals l'onrat en Pere Figuerola, maestre en arts e en medicina, a pregàries d'alcuns notables hòmens, havia ordenat sobre lo bon regiment e cors dels estudis e escoles de la dita ciutat, a profit dels estudiants e a bé de la cosa pública. ${ }^{27}$

El Consell no quiso pillarse los dedos y, como solía hacer en tales casos, designó una comisión revisora constituida por dos juristas, dos médicos, cuatro notarios y otros expertos, cuya elección encargó a los jurados. Unos días después, el 12 de octubre, el Consell volvía a abordar la cuestión, insistiendo en que el reglamento fuera revisado por la comisión designada anteriormente, y en que se llegara a un acuerdo al respecto con el obispo, tras lo cual podría ser puesto en práctica. ${ }^{28}$ Todos estos trámites debieron verse coronados por el éxito, incluidas las negociaciones con el obispo, porque un año más tarde, el 26 de octubre de 1390, el clavario municipal gastó casi dos libras

26 Figuerola habría estudiado en Montpellier en torno a 1370, es decir, después de dejar la regencia de la escuela capitular de gramática, donde sabemos que estuvo al menos hasta 1364 (GARCÍA BALLESTER, L., La medicina a la València medieval. Medicina $i$ societat en un país medieval mediterrani, Edicions Alfons el Magnànim IVEI, Valencia 1988, p. 88).

27 Éste y los sucesivos fragmentos de las actas municipales relativas al proyecto estatutario de 1389 y sus posteriores vicisitudes, corresponden a SANCHIS SIVERA, "La enseñanza en Valencia", CIX, pp. 41-43.

28 (...) que.ls dits capitols sien reconeguts per los declarats en lo dit altre consell; e que, concordats ab lo senyor bisbe o ab son official, sien meses en execució segons continència de aquells. 
en hacer dos copias sobre pergamino de los nuevos estatutos, que fueron clavadas en sendas tablas y entregadas a cada uno de los dos maestros para ser expuestas públicamente en sus escuelas, a fin de que todos conocieran sus derechos y obligaciones. ${ }^{29}$ El texto de estas ordenanzas no se trasladó a los libros de actas del Consell, lo que revela cierta negligencia o, como mínimo, poco aprecio por el valor de la nueva normativa escolar. En todo caso, cabe identificar a los dos maestros con los que enseñaban en los locales de la parroquia de Sant Bartomeu, Gil Remírez y Pere Costa. El hecho de que el municipio se arrogara cierta jurisdicción sobre ambas escuelas, indica que las compraventas realizadas en 1374 le reservaron tal derecho, obviamente porque se hicieron a precio subvencionado.

En la reunión del 12 de diciembre de 1393, cuando los pergaminos debían llevar más de tres años expuestos, el Consell volvió a abordar el asunto para hacerse eco de que, aunque el reglamento había sido observado al principio en las escuelas de la ciudad -es decir, en las escuelas de Valldigna, que el gobierno municipal consideraba ya como propias-, ahora se estaban produciendo transgresiones, ${ }^{30}$ por lo que expresaba su voluntad de revitalizar la normativa de 1389 y ordenaba que fuera copiada e inserta por el escribano en los libros de actas. Vanos deseos. Las páginas destinadas a tal fin quedaron en blanco y el texto se perdió definitivamente. Todo lo que sabemos es que, por una parte, establecía la manera de les lectures e demostraments que en les dites escoles fer-se dejen ara e en esdevenidor, es decir, los programas escolares; y que, por otra, no suponía una alteración efectiva del status quo surgido del conflicto de 1374, pues no pretendía unificar las escuelas de la ciudad, ni siquiera las propias escuelas de Valldigna, que seguían siendo dos. Quizás por esto último no había inquietado al obispo ni a quienes, dentro del municipio, defendían el principio foral de la libertad de enseñanza, que en tales condiciones no tuvieron reparos en permitir a Pere Figuerola, médico eminente, hombre preocupado por la labor pedagógica y buen conocedor del mundo universitario, poner en práctica su ideario educativo. ${ }^{31}$

29 (...) són estats meses e clavats en dues posts, e liurats la I a cascun dels mestres a obs de tenir aquell contínuament cascú en son estudi públicament, per ço que a tots sia cosa manifesta que deuen fer los dits mestres, e que déu ésser fet a aquells.

30 (...) la qual taula e ordenació jassia al començament se observàs, però en aprés e ara, segons fo affermat al present Consell, fo e és estada en algunes coses obmesa.

31 Figuerola fue autor de un breve Regimen sanitatis, escrito en forma de carta a sus hijos, estudiantes en la universidad de Toulouse, donde desgranaba preceptos para el correcto cuidado del cuerpo y de la mente. Thorndike lo fechó en 1415, pero García Ballester señala que Figuerola murió en 1397, lo que obligaría a adelantar la datación del tratado (THORNDIKE, L., "Advice from a Physician to his Sons", Speculum, VI, 1931, pp. 110-114; GARCÍA BALLESTER, La medicina a la València medieval, p. 94). 
Cabe pensar que si en el año 1399 se recurrió a Francesc Eiximenis y a sus compañeros de comisión para redactar nuevos estatutos escolares, fue porque los de Pere Figuerola no respondían a las intenciones del gobierno municipal del momento; y también, que si no fueron requeridos en aquel momento los servicios del propio Figuerola, hasta entonces el más destacado de cuantos habían aconsejado a los jurados en ese asunto, fue porque había fallecido (dos años antes, a decir de García Ballester). No es probable que la necesidad de renovación estuviera en los programas o en los procedimientos lectivos, porque las diferencias de criterio respecto a las propuestas de Figuerola no podían ser grandes, dado el relativo consenso que sobre esta materia existía en la época, sobre todo cuando se trataba de la enseñanza de la gramática y demás artes liberales. ${ }^{32}$ El problema no era técnico, sino político, y se deduce fácilmente del acta que registra el debate entre maestros celebrado el 31 de agosto de 1400, y al que ya nos hemos referido anteriormente. Por primera vez, el Consell se enfrentaba a una propuesta de unificación escolar, y esto suponía no sólo la creación de un centro subvencionado, como podían ser las ya existentes escuelas de Valldigna, sino de uno que reuniera a los maestros más destacados, y cuya actividad se viera decisivamente promocionada por una normativa que prohibiera ejercer la docencia en cualquier otro lugar de la ciudad. Algo que atentaba contra la interpretación que, al hilo de los conflictos precedentes, había hecho el propio gobierno municipal de las libertades forales.

La actitud de quienes rechazaban la política educativa intervencionista, y no debían ser pocos dentro del Consell, respondía a algo más que a un mero prurito legalista; y tampoco era resultado de la improvisación o de la negligencia en la acción de gobierno. En el imaginario social urbano de estos siglos tardomedievales, la instrucción de los jóvenes era un asunto que correspondía, ante todo, al ámbito de los asuntos domésticos. Para compro-

En efecto, en 1414, la viuda del magister Pere Figuerola, Caterina, firmó un recibo por el pago de una pensión censal (Archivo de Protocolos Notariales del Colegio de Corpus Christi, no 26118, Bartomeu Queralt, 29 de mayo de 1414). Carmel Ferragud proporciona algunos datos sobre el comportamiento socioeconómico de Figuerola, que como tantos otros conciudadanos suyos, desempeñó algún cargo parroquial (obrer de Sant Martí en 1386) e invirtió en deuda censal cargada sobre diversos municipios y aljamas del reino (FERRAGUD DOMINGO, C., Medicina i promoció social a la baixa Edat Mitjana (Corona d'Aragó, 1350-1410), CSIC, Madrid 2005, pp. 332 y 604); por su parte, Xavier Renedo hace una interesante comparación entre sus ideas y las del franciscano Eiximenis acerca del valor médico y pedagógico del ejercicio físico (EIXIMENIS, F., Llibres, mestres i sermons. Antologia de textos, ed. de D. Guixeras y X. Renedo, Barcino, Barcelona 2005, pp. 220-221).

32 CRUSELLES, Escuela y sociedad, pp. 186-199. 
barlo basta con acudir a Eiximenis. El franciscano dedicó un considerable esfuerzo argumentativo a exponer una teología del conocimiento donde las ciudades cumplían una función central, puesto que eran el ámbito por excelencia de la enseñanza, el lugar donde en mayor cantidad y calidad se reunían maestros, libros y sermones, de manera que para aprender era necesario venir a ellas; era incluso recomendable que los campesinos enviaran a sus hijos, si querían cumplir con la obligación que habían contraído como padres:

Car en les ciutats l'om és mills informat a tota res de bé que vulla saber, car aquí ha més hòmens scients, e més libres, e més sermons, e més liçons, e més bons eximplis de moltes bones persones que no ha en los lochs manors (...) Per rahó d'açò dix aquell gran philosoff Prometheus que més valia bon hom nodrit en loch notable que bon hom nodirt en loch petit. E dava document als pagesos que fahessen nodrir lurs fills en bons lochs e grans ciutats, si fer-ho podien, car per açò retien mils lur deute a la obligació filial. Per què deya que cascú per natura deu nodrir e informar son fill al mils que pot, com lo fill sia creatura per Déu comanada al pare a ffer-li tota bona obra que puxa per tal que sia mils dispost a servir Déu e a la cosa pública. ${ }^{33}$

Era responsabilidad de los padres, no de la cosa pública, que los niños aprendieran; es más, los buenos ciudadanos no debían cumplir con ese deber mirando tan sólo el provecho propio y del hijo, sino también el de la cosa pública, que necesitaba proveerse para su gobierno de gente bien instruida:

(...) car com lo pare e cascú sia tengut de ajudar a la cosa pública segons son poder, segueix-se que com cascú de la comunitat sia membre d'aquella, que cascú se deu esforçar de dar-li bons membres qui la puxen bé ajudar quant hora sia. Com, donchs, l'om bé informat la puxa mils ajudar que l'om qui és rústech e bestial, seguex-se que los stranys e forans de les bones ciutats deuen lurs fills trametre a les notables ciutats per bona informació, si donchs no y contrasta inpotència e deffalliment de sostenir-hi lo infant o altra rahonable occasió. ${ }^{34}$

La aportación que los poderes públicos -la iglesia, el príncipe e implícitamente, si queremos, el municipio- debían hacer a ese esfuerzo privado, ya lo hemos visto, era abrir escuelas, y éstas debían ser gratuitas para facilitar la extensión del conocimiento al mayor número de personas posible. Sin embargo, en este punto preciso, el de la gratuidad del sistema escolar, Eiximenis se alejaba mucho de la común opinión de sus conciudadanos, y también de la suya propia, si atendemos al contexto socioeconómico en el que habitualmente coloca el aprendizaje literario dentro de su obra. A lo largo de toda ella, por activa y por pasiva, Eiximenis insiste en que aprender es un esfuerzo rentable, porque permite conocer a Dios y ganar la salvación,

33 EIXIMENIS, Dotzé llibre, pp. 44-45.

34 Ídem, p. 45. 
y porque nutre al hombre de aquellas cualidades y principios sin los cuales deja de ser hombre y deviene bestia. A nadie que tuviera los medios suficientes para mantener un modo de vida digno, acorde con su condición social (estament), debía dolerle pagar por adquirir conocimiento, porque en este trámite la avaricia conducía directamente a la ruina del alma:

Per què per açò en especial ascientà Cató son fill en lla mort que totstemps entesés en estudi de bons libres, e de notables consells e de famoses doctrines, car dix ell que:-Pus la vida corporal te leix bastant a ton estament, no.t vulles tacar per hòrrea avarícia, qui.t reta a Déu e al món pudent e diffamat, e.t tolga fer nobleses e entendre en bon saber e en saviesa, car ffoyll és l'om qui per nagun ajust de riquesa, pus que passar pot covinentment segons son estament, desempara estudi de saviesa, per la qual mereix a Déu ésser plasent, e senyorejar al món, e a regir si mateix e ésser honrat e amat per tota creatura (...) car l'om havent saviesa ha Déu, e lo món e si mateix, e sens ella és una gran bèstia indigne de habitar entre.ls hòmens. ${ }^{35}$

Pero no sólo eso, porque además de las teológicas y morales, la educación procuraba también recompensas mundanas: teniéndola, podían adquirirse las "artes lucrativas" y los oficios de la administración. También aquí la responsabilidad recaía en los padres, porque no procurar al hijo los medios de vida más adecuados era sólo un poco menos reprobable que engendrarlo bastardo:

La quarta manera de guanyar diners s'apella artíffica. E aquesta és saber guanyar diners per alguna art lucrativa, o per offici temporal de senyor o de comunitat. Les arts lucratives, més que altres, són art de jurista, de metges, de cambiador, de monader, de mercader e de notari (...) Cascun hom deu dar a son fill la millor art que puxa, segons que deya Zenó philosoff. Per tal deya que lo fill se pot tostemps clamar de son pare en les coses següents, ço és, primerament si no l'engendra legítim o si.l té sens legitimació; segonament, si li posa vil nom; terçament, si l'ha mal nodrit; quartament, si l'ha oblidat en deguts, e paternals, e necessaris e naturals benifficis; quintament, si li ha ensenyada dolenta art de viure, car cascú pot ensenyar a son fill alguna bona art qui sia bona en si o segons la manera e costuma de la terra. ${ }^{36}$

Eiximenis se abstuvo de añadir en este pasaje que el aprendizaje de todas estas profesiones también requería maestros y libros, quizás porque no quería que argumentos tan materialistas contaminaran unos recursos que, dentro de su teología pedagógica, correspondían a la esfera espiritual y a la edificación moral; pero no podía ignorar que las instituciones escolares, eclesiásticas y laicas, atraían a buen número de gentes que buscaban ocasiones de promoción socio-laboral en los conocimientos que allí se impartían; y eso incluía

35 EIXIMENIS, Dotzé llibre, p. 30.

36 Ídem, p. 322. 
también la profesión clerical, como tantos tratadistas venían denunciando desde hacía mucho tiempo. La irrupción del dinero había tenido graves consecuencias en el mundo escolar, porque al calor de las ganancias habían proliferado los maestros simoníacos y los estudiantes que, despreocupándose de la verdadera sabiduría (el conocimiento de Dios), abreviaban sus estudios para adquirir profesiones lucrativas en el mundo de la administración, el derecho y la medicina. Autores reconocidos como Pedro Damiano y Juan de Salisbury ya habían escrito en siglos anteriores contra el poder del dinero en la corte pontificia, contra los clérigos cortesanos empeñados en la carrera de dignidades, contra los clérigos que marchaban a Salerno y Montpellier para aprender medicina y aprovecharse luego de los enfermos ricos, contra los clérigos abogados cuyos excesos habían pretendido limitar, con poco éxito, los padres conciliares de Reims y Letrán. ${ }^{37}$ El caso del estudiante valenciano Jeroni Manyes, aunque un tanto tardío, ilustra bien la actitud con la que muchos acudían a la escuela: en 1426 contrató los servicios de un maestro para que le enseñara gramática y lógica durante dos años, de manera que aprendiera lo bastante para poder adquirir la profesión de notario o de capellán (sufficient a pendre l'art de notaria o de capellà); obviamente, la elección final entre ambas "artes" dependería de las oportunidades que se presentaran en el futuro. ${ }^{38}$ Por tanto, existía al menos un "arte lucrativa" que Eiximenis no había incluido en su lista; y los programas escolares de la época se adaptaban a ella a las mil maravillas, puesto que su primer cometido, tal y como habían querido los reformadores eclesiásticos de los curricula clásicos, era el de formar clérigos.

Resumiendo. En aquel mundo urbano de finales de la Edad Media estaba muy extendida la opinión de que, si la enseñanza de los hijos era competencia y obligación de los padres, y el conocimiento adquirido en las escuelas (el ámbito por excelencia de los maestros y los libros) redundaba en beneficios privados (que los buenos ciudadanos ya pondrían luego al servicio de la cosa pública), no era preciso que el municipio gastara en este asunto más que lo estrictamente necesario para conseguir que en la ciudad existiera una oferta educativa suficiente y a precio razonable, es decir, asequible para quienes constituían los grupos sociales dirigentes. Lo demás era despilfarro, y la enseñanza gratuita una excentricidad, adecuada para los sermones y las lec-

37 RICHÉ, P., "Jean de Salisbury et le monde scolaire du XII siècle", en The World of John Salisbury, Basil Blackwell, Oxford 1984, pp. 39-61, y especialmente 49-52).

38 CRUSELLES GÓMEZ, J. M., "Los estudiantes de la Valencia preuniversitaria: entre la carrera eclesiástica y la sociedad civil", Estudis. Revista de Historia Moderna, 23, 1997, pp. 11-40, y especialmente p. 25. 
turas edificantes, pero sin relación alguna con la realidad. Si la iglesia había sido incapaz de cumplir semejante precepto en sus propias escuelas, ¿cómo podía esperarse que lo asumieran las escuelas municipales? El propio Eiximenis, después de exponer el asunto al principio del Dotzè, pasa sobre él de puntillas, y apenas vuelve a decir palabra sobre la organización y la vida escolar, más allá de las abundantes, estereotipadas y prolijas descripciones del sagrado vínculo entre el maestro-padre y el discípulo-hijo, fuente inagotable de ejemplos moralizantes y sabios consejos. ${ }^{39}$ En conjunto, los ciudadanos y caballeros que gobernaban la ciudad de Valencia a fines del siglo XIV estaban de acuerdo con la importancia que Eiximenis atribuía a la formación literaria de niños y jóvenes, y por motivos similares a los suyos (aunque podemos sospechar que las razones de orden socioeconómico prevalecían sobre las teológico-morales): el problema estaba en la función que correspondía asumir en este asunto a la autoridad pública municipal.

El desinterés por articular una verdadera enseñanza pública puede detectarse en otros lugares del entorno mediterráneo de la época, y ha sido tratado con detalle por los historiadores italianos. Éstos coinciden, a grandes rasgos, en que prevalecía la opinión de que el uso de fondos públicos sólo estaba justificado cuando el juego libre del mercado no bastaba para asegurar la presencia de docentes, y éstos debían ser atraídos mediante subvenciones de un tipo u otro. No era necesario hacerlo en las grandes ciudades, donde una demanda abundante aseguraba las ganancias de los maestros, y la creciente competencia entre ellos unos precios razonables a los clientes; por el contrario, en las ciudades pequeñas, los municipios estaban obligados a desplegar una política intervencionista si querían asegurar los servicios docentes a los ciudadanos, ${ }^{40}$ lo que no incluía a todos los habitantes de la ciudad. Escuela subvencionada no quería decir gratuita, pues siempre se mantuvo el sistema mixto de retribución de los maestros, que obtenían una parte considerable

39 La cuidada antología de textos pedagógicos realizada por David Guixeras y Xavier Renedo ofrece un detallado panorama del pensamiento pedagógico de Eiximenis, ordenado en cuatro ámbitos de socialización -la ciudad, el hogar, la sociedad, la escuela- de presencia desigual dentro de la obra del teólogo franciscano, particularmente por lo que toca al último de ellos. Eiximenis omite el mundo escolar, que más allá de la enunciación de los programas docentes característicos de la época, no asoma sino en algún chascarrillo al estilo de aquel de los juristas de Montpellier (EIXIMENIS, Llibres, mestres i sermons, pp. 209-244).

40 El gobierno veneciano desplegó al mismo tiempo ambas opciones políticas: asalariaba maestros en aquellos lugares de la señoría que por su tamaño y recursos limitados no resultaban atractivos para los docentes, y prescindía de toda intervención en la populosa Venecia (ORTALLI, G., Scuole, maestri e istruzione di base tra Medioevo e Rinascimento. Il caso veneziano, Neri Pozza, Vicenza 1993, pp. 115-130). 
de sus ingresos a partir de salarios privados. Esta política estaba hecha a la medida de las necesidades de reproducción social de los grupos dirigentes, y prescindía de la mayor parte de la población. ${ }^{41}$ El único paso efectivo a favor de una instrucción verdaderamente pública fue, en las ciudades italianas de la Edad Media tardía, admitir gratuitamente a un cierto número de estudiantes pobres en estos centros subvencionados. ${ }^{42}$

En la Valencia de Eiximenis, la gratuidad de la enseñanza no fue objeto de debate en ningún momento. Una vez superada la discusión sobre la preeminencia eclesiástica en el sector educativo, se trataba de establecer el alcance de la política de subvenciones municipales, y en concreto, si éstas debían sumarse simplemente al libre concurso de la oferta, asegurando la apertura de una escuela estable y prestigiosa, pero sin alterar la situación del resto de los maestros "libres", ya fueran clérigos o laicos; o si, por el contrario, era necesario reorganizar profundamente el sector, creando un gran centro escolar en régimen monopolístico que permitiera asegurar la homogeneidad de la práctica docente y, en definitiva, establecer un férreo control de la competencia. El médico Pere Figuerola participaba de esta última manera de pensar, pero no podemos asegurar lo mismo de Eiximenis, si nos atenemos a su obra literaria. Sin embargo, nuestro franciscano era un reglamentista convencido, y aunque en su tratado no expusiera una doctrina clara al respecto, no cabe duda de que se alineó con las posturas más intervencionistas, las que en 1399 buscaban por primera vez la unificación escolar.

El fracaso de ese proyecto, materializado en el debate entre maestros de 1400, no supuso la desaparición del ideario que lo sustentaba. Tres años más tarde, durante la reunión celebrada por el Consell a 2 de junio de 1403, sus defensores volvieron a intentarlo, aunque esta vez por un camino diferente e inédito: establecer un examen municipal para maestros de escuela. La justificación de la medida se situaba explícitamente en los males derivados de la falta de unidad del mundo escolástico urbano, y su oportunidad en el hecho de que, en aquel preciso momento, no podía hacerse otra cosa para combatir dichos males, lo que remitía al obstáculo de la libertad foral de enseñanza y al reciente fracaso estatutario de 1399, aunque también dejaba entrever la

41 PETTI BALBI, G., "Istituzioni cittadine e servizi scolastici nell'Italia centro-settentrionale tra XIII e XV secolo", en Città e servizi sociali nell'Italia dei secoli XII-XV. Atti del XII Convegno Internazionale di Studi (Pistoia, 9-12 ottobre 1987), Centro italiano di studi di storia e d'arte, Pistoia 1990, pp. 21-48, y especialmente pp. 43-45; BRESC, H., 1990, "École et services sociaux dans les cités et les "terres" siciliennes (XIII ${ }^{\mathrm{e}}$-XV ${ }^{e}$ siècles), en Città e servizi sociali, pp. 1-20, y especialmente p. 9.

42 GRENDLER, P. F, La scuola nel Rinascimento italiano, Laterza, Roma-Bari 1991, pp. 25-26. 
posibilidad de que esa situación cambiara en el futuro. Se trataba, en definitiva, de recuperar el principio de la licencia docendi dentro de un contexto normativo diferente:

(...) com les scoles de gramàtica de la ciutat vajen a redolons, de què.s seguexen als escolans e aprenents molts mals nodriments, e s'enviltexen, e d'açò és causa diversitat de maestres; per tal lo dit Consell, concordantment a obviar a les dites coses, com altra pus covinent manera al present no.s trob a honestar les escoles $e$ tolre.ls de molts vicis que la següent; estatuex perpetualment en quant és en ell, que d'ací avant alcun maestre o bacheller o altre qui vulla tenir escoles a legir de gramàtica, lógica e d'altres arts, no puxa emparar e tenir escola e legir de les dites sciències o alcuna de aquells, si donchs o primerament no és examinat e aprovat per los dits honorables jurats o Concell de la ciutat. ${ }^{43}$

La imitación de los anteriores procedimientos eclesiásticos resulta evidente: los jurados, como antes el obispo, no podían impedir que los maestros se establecieran libremente, pero sí juzgar su capacidad científica y moral para enseñar, introduciendo de soslayo, mediante una norma de rango secundario, el principio de aptitud que el polémico fuero había omitido. Unas reminiscencias clericales que aún resultan más evidentes desde el momento en que, al contrario de lo ocurrido con los estatutos de 1399, se invitaba a la catedral a adherirse a la propuesta, ofreciéndole incluso la posibilidad de crear tribunales de examen mixtos, aunque el municipio también afirmaba su firme intención de aplicar en cualquier caso la nueva normativa:

E acomanà lo dit Concell als honorables jurats, que conviden lo Capítol de la Seu de València a consentir al present estatut o a fer-ne semblant, e que la examinació e aprovació dessús dites, si consentir-hi volrà lo dit Capitol, puxen ésser fetes per aquell e los honorables jurats de la ciutat que són o seran; e si consentir no y volrà lo dit Capítol, o no.s volrà concordar a aquestes coses, romanga lo dit estatud de part de la ciutat en son ésser e fermetat. ${ }^{44}$

Los maestros quedaban así equiparados a otros profesionales liberales (abogados, notarios, corredores) cuya práctica estaba sometida a la autorización y el control municipal; y como ellos, quienes ejercieran sin la debida aprobación serían reos de la justicia ordinaria, quedarían inhabilitados y, en este caso particular, incurrirían en una severa multa de diez morabatines de oro por cada infracción.

No conocemos la respuesta que dio el Cabildo catedral a tan singular propuesta, ni si llegó a realizarse alguno de estos exámenes. Cabe pensar que, de haber sido así, se hubieran registrado en los libros del justicia civil, como se hacía con los exámenes de los notarios y médicos. Provisionalmente,

43 Archivo Municipal de Valencia, Manuals de Consells, A-22, fol. 246.

44 Ibídem. 
y en ausencia de cualquier información que confirme la puesta en práctica del proyecto, debemos añadirlo al catálogo de fracasos del intervencionismo educativo municipal. Sin embargo, tampoco en esta ocasión los intervencionistas se arredraron. En 1405 volvieron a redactarse nuevos estatutos para las escuelas de gramática, promovidos en esta ocasión por el notario Pere Ferrando, uno de los integrantes de la comisión encabezada por Eiximenis, lo que nos induce a pensar que, en lo fundamental, las diferencias entre ambos proyectos estatutarios debieron ser mínimas. ${ }^{45}$ Pero los resultados fueron también los mismos. Como en ocasiones anteriores, el texto no fue trasladado a las actas municipales: un hecho demasiado repetido como para considerarlo fruto del azar. Nada vuelve a saberse de este conato ordenancista, que no debió superar el correspondiente examen jurídico, pero no cabe duda de que el principio de unificación escolar que había animado la comisión de 1399, seguía vivo; y cuajó de nuevo a partir de 1407, cuando el Consell, en la reunión del día 22 de febrero, decidió crear una nueva escuela municipal en la plaza de Sant Llorenç.

Como las anteriores, esta nueva intervención de 1407 se justificaba en el mal estado de la enseñanza y en la necesidad de corregirlo, que en términos retóricos se expresaba mediante un tópico, el de la cabeza y los miembros, que en esta Valencia de principios del siglo XV remite a las obras de Eiximenis, que cualquiera podía consultar en la sala de la ciudad:

(...) les escoles e lo regiment de aquelles mereixen correcció, mellorament e adop, axí en lo cap com en los membres, e axí en la conversació e statge e alberch, com en salaris de maestre major e bacheller e cambrers, e altres coses les quals ab hulls chichs no.s podien ne.s devien sostenir o passar sens donar remey. ${ }^{46}$

Una comisión constituida por los jurados, los abogados municipales y un grupo de prohombres (entre ellos otro jurista, dos notarios y un conseller de la parroquia de Sant Llorenç), ${ }^{47}$ debía ocuparse de todo lo relativo a las instalaciones y la ordenación de la docencia, a fin de que los hijos de la ciudad (es decir, los vástagos de los grupos sociales que gobernaban la ciudad),

45 Este reglamento fue presentado ante el Consell en la reunión celebrada el día 28 de abril de 1405, y remitido a los jurados para su examen (VIVES LIERN, Las casas de los estudios, p. 29).

46 Ídem, p. 41.

47 Los seis prohombres incluidos en la comisión formaban parte de un Consell que había sido designado directamente por el rey en junio de 1406, en medio de los conflictos de bandos que azotaban en esa época la vida política ciudadana (Libre de Memòries de diversos sucesos e fets memorables e de coses senyalades de la ciutat e regne de València,1308-1644, introducción y notas de S. Carreres Zacarés, vol. 1, Acción Bibliográfica Valenciana, Valencia 1930, pp. 282-285). 
pudieran formarse adecuadamente sin que sus padres hubieran de afrontar excesivos gastos, puesto que el Consell estaba dispuesto a hacerlo por ellos. Y ahora sí, la justificación de la medida remitía punto por punto a la retórica eiximeniana, con el municipio actuando en el papel del padre que no debía reparar en gastos cuando de la educación del hijo se trataba:

(...) los fills de la ciutat sien be instruits de sciència e bones costumes sens càrrech de pagar salaris immoderats, dient lo present Consell que en allò no.s devia plànyer messió o despessa per haver fills bons e bé nodrits e instruïts de sciència. ${ }^{48}$

La diferencia fundamental respecto a las otras comisiones creadas anteriormente para hacer las mismas cosas o similares, es que en esta ocasión se llevaron a la práctica. Entre 1407 y 1411, los consejos y juradurías que se sucedieron en el gobierno municipal, desarrollaron una política común e ininterrumpida que condujo a la fundación de la Escola major de Sant Llorenç en 1412. En la reunión del Consell celebrada el 28 de febrero de 1410, cuando todavía no estaban terminadas las negociaciones que condujeron a la compra de los locales, se tomó la decisión de redactar nuevos estatutos escolares y se nombró la comisión correspondiente. Formaba parte de ella un viejo conocido, ducho ya en estos menesteres: el notario Pere Ferrando; y de nuevo se recurría al topos retórico de la cabeza y los miembros para definir la tarea a realizar:

(...) veesen e mellorasen e ordenassen en e de les dites escoles, en lo cap e en los membres, per raon del studi e doctrina e salaris, ço que.ls paregués ésser faedor e deure ésser possat en tall e orde e regla e manera bona a instrucció e doctrina e bones costums dels fills de la ciutat, he u reduïssen en memòria per capitols referidors al Concell de la ciutat. ${ }^{49}$

También formaban parte de la comisión el jurista Guillem Estrader, que había sido abogado pensionado de la ciudad, y un Pere Carcassona de cuyas circunstancias nada sabemos, pero que es homónimo del Pere Carcasona, clérigo y bachiller en artes, que casi treinta años antes actuaba como regente de la escuela de gramática del Cabildo. ${ }^{50}$ Si se tratara de la misma persona, su presencia en esta comisión de expertos guardaría relación con su calidad como tal (no hubiera sido la primera vez que los jurados requerían consejo a un antiguo regente de las escuelas capitulares), pero también con el hecho de que el municipio estaba decidido, en esta ocasión, a contar con el acuerdo

48 VIVES LIERN, Las casas de los estudios, p. 41.

49 SANCHIS SIVERA, "La enseñanza en Valencia", CIX, p. 47.

50 Archivo del Reino de Valencia, Registros Notariales, 11.203, notario desconocido, 31 de agosto 1383. 
y la colaboración de la catedral. En la reunión del 11 de octubre de 1411, el Consell dejó constancia explícita de sus intenciones, encargando a los jurados la misión de concertar con el Cabildo los nuevos estatutos escolares, ${ }^{51}$ que unos meses más tarde fueron aprobados tanto por la catedral como por el Consell. Éste lo hizo en la sesión celebrada el día 5 de enero de 1412, y en el acta se reconocía explícitamente que la nueva escuela era resultado de la colaboración entre ambos poderes, que debían elegir al maestro regente de común acuerdo. Además, el nuevo reglamento recogía, en su primer capítulo, las dos medidas que habían estado en el centro de todas las discusiones sobre política escolar desde 1374: el examen de los maestros y, sobre todo, la unificación de las escuelas:

Quod nullus legat, doceat vel instruat, publice vel occulte, in civitate Valentie, de grammatica, logica vel philosophia per se et ut magister, nisi fuerit sufficienter examinatus; et tunc non legat nisi in scola qua nunc noviter est ordinata per reverendissimum dominum episcopum et suum honorabile Capitulum, et Consilium dicte civitatis. ${ }^{52}$

Se prescribía la obligatoriedad del examen de aptitud para todos los maestros que desearan enseñar artes liberales en la ciudad, pero no se establecían las condiciones en que debía llevarse a cabo, quizás porque no se había convenido aún la constitución de tribunales mixtos, como se preveía en 1403, u otro sistema alternativo, como podía ser el de encomendar el examen de los maestros eclesiásticos a la iglesia, y el de los laicos al municipio. De forma complementaria, la unificación escolar se instauraba por la vía negativa: nadie podría enseñar en la ciudad si no lo hacía en la nueva escuela, incurriendo los infractores en la gravosa pena de 50 florines de oro, veintisiete libras y media de la moneda de cuenta valenciana, que pasarían a manos del obispo y la catedral si el condenado era persona eclesiástica, o del municipio en caso de que fuera laico (en este punto las competencias respectivas de ambos poderes sí estaban netamente definidas).

La relación que estas disposiciones guardan con todo el esfuerzo intervencionista anterior resulta evidente. Los estatutos escolares de 1412 recopilaron medidas políticas que habían sido planteadas con anterioridad, como las dos señaladas, y en consecuencia hemos de pensar que también

51 (...) que los honorables jurats tracten ab lo Capitol de la Seu e.n facen capítols tals com los parega ésser faedors, axí en la doctrina e lectura e regiment, com en salaris (TEIXIDOR, Estudios de Valencia, p. 109).

52 Puede verse el texto completo del reglamento escolar de 1412 en SANCHIS SIVERA, "La enseñanza en Valencia", CIX, pp. 48-52; y en VIVES LIERN, Las casas de los estudios, pp. 105-107; los fragmentos que aquí incluimos corresponden a la versión de Sanchis Sivera. 
recogió una buena cantidad de ideas y preceptos relativos a la organización (personal docente, jerarquía académica, salarios...) y al programa lectivo (materias, libros, horarios, procedimientos didácticos...) En conjunto, debemos considerar que ésta fue una obra colectiva, fruto de esfuerzos y conocimientos diversos, que pudo beneficiarse de la tenacidad reglamentista del notario Pere Ferrando, de la experiencia del médico Pere Figuerola, antiguo maestro de escuela, de la pedagogía moral del teólogo Francesc Eiximenis, y del conocimiento que estos dos últimos reunían acerca de los contenidos y procedimientos escolásticos vinculados al estudio de las artes liberales (que era un requisito necesario para obtener los grados académicos en medicina y teología). Eiximenis se encontraba en Valencia cuando Figuerola compuso el fallido reglamento de 1389, y no parece razonable que la comisión de 1399, que aquel encabezó, no tuviera acceso al texto compuesto diez años antes, al que se debieron hacer entonces las oportunas modificaciones -añadiendo, por ejemplo, el precepto de unificación de las escuelas-, que a su vez serían revisadas en 1405 y 1412. Desafortunadamente, sólo conservamos el último texto, el de 1412, pero al menos en dos lugares concretos se nos antoja reconocer la mano de nuestro franciscano. Primero, y de manera bastante palpable, en uno de los capítulos relativos a las lecciones (actos) que el maestro regente debía impartir:

Item, quod quolibet anno legat aliquem librum de logica in quo sint compilate, breviter et utiliter, materia logice secundum quos istis temporibus communiter pertractantur per magistros Parisius et Oxonie.

Es decir, que las lecciones de lógica de la Escola Major debían impartirse según las maneras propias de las universidades de París y Oxford. Considerando que Pere Figuerola estudió en Montpellier, no parece probable que ningún otro miembro de las sucesivas comisiones escolares valencianas, todos ellos notarios y juristas, hubiera estudiado en París, a donde acudían preferentemente los teólogos, y mucho menos en Oxford, que por su ubicación resultaba una mala alternativa a los centros del sur de Francia e Italia, o a la propia universidad de Lleida, lugares mucho más cercanos y con notable tradición en los estudios jurídicos. La prescripción concuerda, sin embargo, con el aprecio que Eiximenis sentía por los lugares en los que él mismo había estudiado, y que eran también los centros principales del sistema de educación superior de las órdenes mendicantes. ${ }^{53}$ Así, en la particular interpretación eiximeniana de la translatio studii, la transmisión del conocimiento

53 VERGER, J., "Studia et universités", en Le Scuole degli ordini mendicanti (sec. XIII-XIV). Convegni del Centro di Storia sulla Spiritualita Medievale, XVII (11-14 ottobre 1976), Todi 1978, pp. 173-203. 
por la vía de las grandes edificaciones urbanas, París había heredado directamente el saber de Grecia y Roma; y desde allí, por una ruta similar a la que el propio Eiximenis debió seguir para llegar a Oxford, la ciencia había recalado en Inglaterra, on ha diverses e notables estudis; y desde todos estos lugares se había extendido después al resto del mundo. ${ }^{54}$ París y Oxford encabezaban, por supuesto, su catálogo personal de las grandes universidades europeas, dentro del cual Bolonia ocupaba una posición intermedia y las hispánicas Lleida y Salamanca quedaban relegadas al final:

Per satisfer, encara, a tota la comunitat crestiana, ha la santa Esgleya instituïdes, o diputades, e privilegiades e fort exaltades moltes honorables ciutats en les quals ha posats studis de diverses sciències, axi com a París, de theologia, e a Oxònia e a Cantabrígia, qui són en Anglaterra, e a Tholosa, de la santa theologia, e aprés a Bulunya, e a Perusa, en Avinyó, e a Munt Pasler, e a Leyda e a Salamancha de dret canònic e civil..$^{55}$

En segundo lugar, y aunque este argumento es mucho más indirecto, los estatutos escolares de 1412 incluían la instrucción religiosa dentro de las obligaciones lectivas del maestro principal:

(...) post instruat scolares aliqualiter in doctrina et lege Sacri Evangelii et fidey catholice, videlicet docendo eos decem precepta, articulos fidey, que sunt peccata mortalia, que sunt opera misericordie, et huiusmodi.

Esto, aunque expuesto en un orden meticuloso que recuerda vivamente las prescripciones eiximenianas, no deja de responder en términos generales a las concepciones educativas propias de la época, y pudo ser añadido a raíz de la revisión que el Cabildo catedral hizo del texto. Sin embargo, llama poderosamente la atención el hecho de que no se contemplara algo así en los capítulos acordados sólo unos años antes, en 1398, para regir la escuela subvencionada por la catedral. ${ }^{56}$

La escuela de Sant Llorenç supuso un notorio triunfo para los partidarios del intervencionismo escolástico municipal, pero no erradicó la opinión contraria, que se encontraba firmemente asentada entre los gobernantes. Las líneas añadidas por el escribano del Consell al pie del acta de aprobación de los nuevos estatutos escolares, resultan lo bastante expresivas: los jurados Francesc Corbit y Gabriel Fernández denunciaron que el texto conculcaba la legislación foral y se negaron a ratificarlo:

Super dictos capitulos contradixerunt venerabilis Franciscus Corbit et Gabriel Fernandes, iurati, in quantum videntur facere contra foros, privilegia et libertates civitatis et civium suorum.

54 EIXIMENIS, Dotzé llibre, p. 43.

55 Ídem, p. 88.

56 SANCHIS SIVERA, "La enseñanza en Valencia", CIX, pp. 67-74. 
No entraremos aquí en las causas por las cuales la escuela de Sant Llorenç tuvo una vida tan agitada como breve. En algún momento del año 1411, la dirección del centro fue puesta en manos de una sociedad de maestros integrada por dos eclesiásticos y un laico, y los conflictos entre ellos parecen haber comenzado antes incluso de que se aprobaran oficialmente los estatutos. Con la marcha sucesiva de ambos clérigos, la sociedad se disolvió definitivamente en diciembre de 1412, haciéndose cargo de la escuela el socio restante, Martí de Sohiça, quien la mantuvo abierta hasta julio de 1414. Este fue el último curso escolar: el siguiente día 6 de noviembre, el municipio vendió la casa de la plaza de Sant Llorenç a la familia Centelles, y andando el tiempo se edificó sobre ella el palacio de los Borja, y más recientemente la sede del parlamento autonómico valenciano.

Las ordenanzas escolares de 1412 siguieron en vigor durante los años siguientes, suspendidas sobre la cabeza de cuantos, sin duda, continuaron practicando la docencia libremente en la ciudad. En 1416, los jurados hicieron uso de ellas para intentar cerrar la escuela de Joan d'Ordós, un clérigo que había formado parte de la Escola Major de Sant Llorenç, en lo que parece una evidente represalia. El maestro denunció el caso ante el tribunal de la Gobernación, alegando que se trataba de un atentado contra los fueros del reino, y concretamente contra aquel que sancionaba la libertad de enseñanza. Los jurados perdieron el pleito y los estatutos cayeron en el olvido.

Por fin resignado a la estrechez del marco legal, el municipio redimensionó el alcance de su política educativa, devolviéndola a un punto muy similar al de 1373, que consistía en subvencionar parcialmente una escuela a fin de abaratar el precio de la enseñanza, aunque evitando cualquier tentación monopolista, es decir, renunciando al principio de unificación escolar que se había introducido en $1399,{ }^{57}$ y que no volvió a reaparecer hasta un siglo más tarde, en 1499, como parte de la iniciativa mucho más ambiciosa de crear un Estudio General. Se ordenó entonces que nadie pudiera enseñar en otro sitio que no fuera el inmueble de la calle de la Nave, en la parroquia de Sant Andreu, y eso aunque los fueros dispusieran lo contrario:

(...) que en la casa dessús dita, comprada per la dita ciutat, la qual és construhida en la parròquia de Sent Andreu, prop lo vall, se tinga lo dit Col-legi e Studi General de gramàtica, lóchiqa, filosofia natural e moral, metafisica e altres arts liberals; e no en altre loch ni casa de la dita ciutat, no obstant qualsevol disposició de dret e de furs e de privilegis o de ordinació e stabliment en contrari fets e ordenats. ${ }^{58}$

57 CRUSELLES GÓMEZ, J. M., "El maestro Joan de Miravet y la escuela municipal de Valencia en la primera mitad del siglo XV", Saitabi, 55, 2008, pp. 93-108.

58 Archivo Municipal de Valencia, Manuals de Consells, A-49, fol. 316. 
Ahora sí, la vieja controversia quedaba superada y la política educativa municipal entraba en una época distinta, caracterizada por nuevos estímulos y problemas, a la que tradicionalmente los historiadores han prestado mucha más atención. Una época que Sanchis Sivera no dudó en calificar como post-foral, por cuanto prescindía de un principio jurídico, el de la completa libertad de enseñanza establecido por el rey Jaime I, que había marcado decididamente, y en general obstaculizado de forma insuperable, todas las actuaciones anteriores en dicha materia. 